\title{
Sensory modality and the word-frequency effect
}

\author{
ALFRED T. LEE, OVID J. L. TZENG, LINDA C. GARRO, AND DAISY L. HUNG \\ University of California, Riverside, California 92521
}

\begin{abstract}
Two experiments were conducted to examine whether the word-frequency effect in recognition memory is primarily a modality-dependent phenomenon. In the first experiment, the presentation modality of a target word was varied orthogonally during the input of the test phases. In the second, the subjects were forced to process each input word at the letter-byletter level, thus minimizing the orthographical differences between the high- and low-frequency words. The word-frequency effect was found in every experimental condition and should be considered a modality-independent phenomenon. A semantically based interpretation of this effect was proposed.
\end{abstract}

When a list of to-be-remembered words is presented to a subject, subsequent recognition of these words depends, to a large extent, on the frequency with which each such word occurs in the printed language. Thus, a word with a low frequency of occurrence, when later intermixed with other words not originally presented, is more likely to be correctly identified as a member of the original list than a word with a high frequency of occurrence. This superiority of rare over common words in recognition memory is theoretically important because the direction of the effect is just opposite to the word-frequency effect one obtains in perceptual studies (Broadbent, 1967) and recall memory studies (Hall, 1954; Kintsch, 1970a). Moreover, this reversed effect in recognition memory has been shown to be a very robust phenomenon (Crowder, 1976; Gregg, 1976; McCormack, 1972).

A number of explanations have been advanced to account for the word-frequency effect in recognition. For example, an intuitively appealing view is that rare-word recognition could be superior due to the subject's greater attentiveness to unfamiliar words relative to familiar ones. It has been shown that lowfrequency words do require different processing demands from subjects. For example, common words have shorter verbal response times in reading than do rare words (Berry, 1971), and anagram problems are more easily solved if the solution words have a high normative frequency (Mayzner \& Tresselt, 1958). Moreover, in word-identification tasks, auditorily presented common words can be identified at a lower amplitude than can rare words and require a shorter exposure time in visual tachistoscopic presentation (Kahneman, 1973). It appears that low-frequency words demand more analysis by the subject and that such increased atten-

This study was supported by an intramural research grant from the Academic Senate of the University of California, Riverside, to the second author. We thank Leah Light for a critical reading of the first draft. Requests for reprints should be sent to Ovid Tzeng, Department of Psychology, University of California, Riverside, California 92521. tiveness may enhance subsequent recognition performance. Thus, in a mixed-list design (i.e., both highand low-frequency words are presented together in a study list), the word-frequency effect was attributed to the differential amount of attention paid to the two classes of words during the time of list presentation. However, this explanation was found to be inadequate by the demonstration that the word-frequency effect was also observed in an unmixed-list design. Kinsbourne and George (1974) have demonstrated rare-word recognition superiority when the subject studies and is tested with only words of the same frequency level. If a subject studies and is tested with only low-frequency or only high-frequency words, rare-word recognition superiority cannot be attributable to the differential allocation of study time. Any explanation of the word-frequency effect must therefore take into consideration the different characteristics of these word populations that covary with frequency.

Recent attempts to account for the frequency effect have stressed the important differences in structural and semantic attributes of the two word groups. Common words are known to share graphemic characteristics with other common words to a greater extent than do rare words with other rare words (Landauer \& Streeter, 1973). Word length (i.e., number of letters) also varies inversely with word frequency (Zipf, 1935). Furthermore, rare words are lower in associative meaningful. ness (Paivio, Yuille, \& Madigan, 1968) and have meanings less sensitive to shifts in semantic context than common words (Reder, Anderson, \& Bjork, 1974).

Lockhart, Craik, and Jacoby (1976) have suggested an explanation for rare-word recognition superiority based on the levels-of-processing view of Craik and Lockhart (1972). Since rare words share few graphemic and semantic characteristics with other rare words, perceptual and cognitive operations performed on such words tend to form relatively unique traces compared to those formed from common words. Further, since rare words tend to have similar semantic encodings on subsequent occasions, the traces of these encodings are 
likely to overlap to a greater extent than those of common words.

Lockhart et al. (1976) focused on the encoded structural features of a rare word that are the result of attentiveness to surface features during the slowed process of extracting meaning. This aspect of the explanation is in accord with the emphasis of Underwood (1969) on the discriminative function played by the structural aspects of words in recognition memory. Generation-recognition models (Anderson \& Bower, 1972, 1974; Bahrick, 1970; Glanzer \& Bowles, 1976; Kintsch, 1970b; Reder et al., 1974), however, emphasize the semantic uniqueness of rare words. Contextual tagging or marking of word meanings encoded during study are matched to those occurring during recognition testing. Since rare-word meaning is relatively stable, the matching of contextual markings between study and testing is facilitated by access to the same "sense" of a word during recognition.

In both the levels-of-processing and the generationrecognition explanations, the stable semantic characteristics of rare words play a role in enhancing recognition, although for different reasons. The contribution of structural attributes of words in recognition, however, is assumed to be essential in the former view but of minimal significance in the latter. An examination of the relative contribution of the semantic and sensory aspects of a word on its subsequent recognition by varying the sensory modality of item presentation during the study and test phases would be of value in determining the efficacy of these models. However, the word-frequency effect has been assessed in past studies only with either visual or auditory modes of both study and testing. No study has contrasted the magnitude of the effect between modalities, nor is it known whether recognition testing in a sensory modality other than that emphasized during study would alter the effect. Yet, Penney (1975) has shown that certain memorial phenomena occur only with auditory presentation or only with visual presenta tion. Moreover, since it is known that long-term encod. ing of sensory attributes of verbal information occurs (Kolers, 1976; Nelson, Brooks, \& Wheeler, 1975; Nelson, Wheeler, Borden, \& Brooks, 1974), changing the modality of recognition testing may deleteriously affect word recognition. Specifically, if rare-word recognition is due to the relative uniqueness of encoded graphemic characteristics, shifting to an auditory test mode should reduce it. Also, rare-word phonemic characteristics, though not similar to common words (Frederiksen, 1971), do not appear to have a demonstrable uniqueness when compared to other rare words. This suggests that auditory presentation and testing may also reduce the effect compared to the visual mode. On the other hand, if the effect is a modality-independent phenomenon, one would expect to find the magnitude of the effect unchanged by testing recognition in a different modality. Thus, visual study and auditory testing (as well as the reverse) should yield an equivalent recognition superiority for rare words, as should same-modality compared to different-modality encoding of study and test items.

The present study was therefore designed to assess the relative importance, if any, of sensory modality on the word-frequency effect. In Experiment 1, factorial treatment combinations of visual and auditory modalities with study and subsequent recognition testing were administered for lists containing high-and low-frequency words. Experiment 2 varied the structural characteristics of both common and rare words within the visual mode in order to assess the contribution of these attributes in word recognition.

\section{EXPERIMENT 1}

\section{Method}

Subjects. Eighty undergraduate students at the University of California were paid for their participation in this study. All subjects were tested individually.

Design. The words were presented in either visual $(V)$ or auditory (A) mode during acquisition and were tested in either mode during recognition. Thus, there were four between-subjects groups. Word frequency (high or low) was another factor. Therefore, the experiment was a 2 by 2 by 2 factorial design, with the last factor as a within-subjects variable.

Materials and Apparatus. Words used in this study were selected from the norms of Paivio, Yuille, and Madigan (1968). Two lists were constructed, each containing 35 high- (A or AA) and 35 low- (0-5) frequency words; the lists were counterbalanced across subjects such that half received one list for study and half received the same list as new words in testing. Homonyms were excluded and, within each list, high- and lowfrequency words were matched for concreteness (mean $=6.1$ ), word length (mean $=6.6$ ), and number of syllables (mean $=2.1$ ).

For visual presentation, each word was back projected on a $25 \times 45 \mathrm{~cm}$ projection screen placed $60 \mathrm{~cm}$ from the subject. An externally programmed Kodak carousel projector was used for individual display of items at a predetermined rate. For auditory conditions, items were prerecorded on one channel of a stereo cassette deck and played back through a loudspeaker positioned in front of the subject.

Procedure. Each subject was presented with a randomized list of 70 to-be-remembered words, immediately followed by 1 min of backward counting. A list of 140 words, 70 old and 70 new, was then presented. The subject responded to each item by marking an answer sheet "yes" if the item was presented during study and "no" if it was not.

Visual items were presented for 2 sec each during the study phase and for $5 \mathrm{sec}$ in the test phase, with a 650 -msec blank interitem interval in both phases. To minimize differential rehearsal for modalities, auditory items were given at a rate of one every $2 \mathrm{sec}$ for study and one every $5 \mathrm{sec}$ for testing. Subjects overtly verbalized items in all conditions.

A brief practice session with digits was given to each subject prior to the main experimental periods.

\section{Results and Discussion}

Tabled values of $d^{\prime}$ and $\beta$ (Freeman, 1973) were determined from the hit and false alarm rates for each subject. Mean d' and $\beta$ values for all treatment combinations are shown in Table 1. The averaged d's across subjects and word frequency for Conditions VV, VA, $A A$, and AV were $3.05,2.62,2.41$, and 2.28 , respectively. 
Table 1

Mean $d^{\prime}$ and $\beta$ Values for High- and Low-Frequency Words as a Function of Modality Combination of Study and Test

\begin{tabular}{ccccccc}
\multirow{2}{*}{$\begin{array}{c}\text { Word } \\
\text { Frequency }\end{array}$} & \multicolumn{5}{c}{ Modality Combination } \\
\cline { 2 - 7 } & & VV & VA & AA & AV & Mean \\
\hline \multirow{2}{*}{ High } & $\mathrm{d}^{\prime}$ & 2.27 & 2.04 & 2.03 & 1.85 & 2.05 \\
& $\beta$ & 2.48 & 3.85 & 2.71 & 2.82 & 2.97 \\
\multirow{3}{*}{ Low } & $\mathrm{d}^{\prime}$ & 3.84 & 3.20 & 2.79 & 2.71 & 3.13 \\
& $\beta$ & 4.39 & 3.60 & 3.29 & 4.28 & 3.89 \\
\multirow{2}{*}{ Mean } & $\mathrm{d}^{\prime}$ & 3.05 & 2.62 & 2.41 & 2.28 & \\
& $\beta$ & 3.44 & 3.72 & 3.00 & 3.55 & \\
\hline
\end{tabular}

Note- $V V=$ visual-visual; $\quad V A=$ visual-auditory; $A A=$ auditory. auditory; $A V=$ auditory-visual.

An analysis of variance (ANOVA) revealed a significant effect of study mode $[\mathrm{F}(1,76)=7.20, \mathrm{p}<.01, \mathrm{MSe}=$ 1.33] and of word frequency $[F(1,76)=101.61$, $\mathrm{p}<.001, \quad \mathrm{MSe}=1.33$ ]. A multiple comparison (Newman-Keuls) of d's for high- and low-frequency words under each of the four modality conditions showed a reliable $(p<.01)$ superiority of rare-word recognition for all conditions. The interaction of Study Mode by Word. Frequency was also significant $[F(1,76)=5.92, p<.025, \mathrm{MSe}=.52]$. Rare-word recognition was thus further enhanced with visual compared to auditory study mode. No other reliable effects were found.

Sensory modality of presentation did not appear to affect subject's decision criterion. An ANOVA of the $\beta$ values for the eight treatment combinations revealed no reliable criterion shifts for any of the main effects or interactions.

Demonstration of the word-frequency effect did not appear to be contingent upon the sensory modality of presentation. The effect occurred whether study and testing conditions were visual or auditory and whether the same or different modality was employed. The magnitude of the effect, however, was influenced by input modality. A greater difference in d's for recognition of high-and low-frequency words exists for the visual as compared to the auditory study mode. The difference in mean d's between high-and low-frequency words was 1.37 for the visual study mode and .81 for the auditory study mode.

A possible explanation for the increased recognition probability of low-frequency words when they are presented visually rather than auditorily during the study phase may be their comparative graphemic uniqueness. Orthographic characteristics of rare words may provide the additional distinctiveness in memory which further enhances subsequent recognition when compared to common words. Interestingly, access to these encoded graphemic attributes appears to require only reinstantiation of word meaning, as evidenced by the absence of any test modality effect in this study.

If the magnitude of the word-frequency effect is partly a function of the differences in orthography for the two word populations, then it should be possible to demonstrate changes in the size of the effect within the visual modality. For example, we can minimize the orthographical differences between the high-and lowfrequency words by forcing the subject to process each word at the letter-by-letter level such that the orthographical cues would not be a special property of only the low-frequency words. One way to achieve this purpose is to present each word in mixed typecases. That is, every other letter in a word was typed in capitals in order to disturb word identification and make it more difficult for the subject to process words at levels higher than the letter. Thus, the second experiment was conducted to test the prediction that minimizing the orthographical difference between the high- and low. frequency words would also minimize, if any, the wordfrequency effect in recognition memory.

\section{EXPERIMENT 2}

\section{Method}

Subjects. Eighty subjects selected from the same population as Experiment 1 were randomly assigned to the four experimental groups, with 20 subjects in each condition. Subjects were tested individually.

Design. The same 2 by 2 by 2 factorial design used in Experiment 1 was employed again. The two between-subjects factors were print type (normal or alternating) and presentation phase (study or test), with the within-subjects factor of word frequency (high or low).

Materials and Apparatus. The same materials and apparatus were used as in Experiment 1. However, letters of each word in the lists employed in Experiment 1 were typed in alternating upper- and lowercases for the alternating condition and all in uppercase for the normal condition. For instance, the word VALLEY was presented as VaLlEy or vAlLeY in the alternating condition. It should be noted that in the condition where both study and test phases were under the alternating condition, the typing format of the target words always remained the same in the test list as in the original study list. For example, if vAlLeY was presented in the study list, vAlLeY (rather than VaLIEy) was also presented in the test list.

Procedure. All aspects of the procedure were identical to those of Experiment 1. Subjects, however, did not overtly verbalize presented words in this experiment. (As in Experiment 1, a brief practice session preceded the present experiment.)

After completing the main experiment, a control condition (with 20 additional subjects from the same source as described above) was run in which all words in both the study and test lists were presented in mixed-type print, similar to the AA (alternating during the study and alternating during the test) condition of the main experiment. However, the prints of the target words were always in opposite format between study and test (e.g., VaLlEy vs. valLeY). The purpose of this control condition was to investigate whether preserving the same typing format would improve recognition performance.

\section{Results and Discussion}

The mean $d^{\prime}$ and $\beta$ values for each of the four treatment groups for the high- and low-frequency words are shown in Table 2 . Results of the added control group $\left(\mathrm{AA}_{d}\right)$ are also presented in Table 2. A t test 
Table 2

Mean $d^{\prime}$ and $\beta$ Values for High- and Low-Frequency Words as a Function of Print Combination of Study and Test

\begin{tabular}{|c|c|c|c|c|c|c|c|}
\hline \multirow{2}{*}{\multicolumn{2}{|c|}{$\begin{array}{c}\text { Word } \\
\text { Frequency }\end{array}$}} & \multicolumn{6}{|c|}{ Print Combination } \\
\hline & & \multirow{2}{*}{$\begin{array}{l}\mathrm{NN} \\
2.87 \\
2.60\end{array}$} & \multirow{2}{*}{$\frac{N A}{3.05}$} & \multirow{2}{*}{ 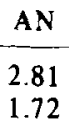 } & \multirow{2}{*}{$\begin{array}{c}\mathbf{A A}_{\mathbf{s}} \\
2.70 \\
2.29\end{array}$} & \multirow{2}{*}{ 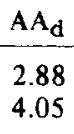 } & \multirow{2}{*}{$\begin{array}{c}\text { Mean } \\
2.87 \\
2.75\end{array}$} \\
\hline High & $\begin{array}{l}d^{\prime} \\
\beta\end{array}$ & & & & & & \\
\hline Low & $\begin{array}{l}d^{\prime} \\
\beta\end{array}$ & $\begin{array}{l}3.50 \\
3.80\end{array}$ & $\begin{array}{l}3.58 \\
4.27\end{array}$ & $\begin{array}{l}3.41 \\
2.10\end{array}$ & $\begin{array}{l}3.14 \\
2.89\end{array}$ & $\begin{array}{l}3.25 \\
4.03\end{array}$ & $\begin{array}{l}3.33 \\
3.42\end{array}$ \\
\hline Mean & $\begin{array}{l}\mathrm{d}^{\prime} \\
\beta\end{array}$ & $\begin{array}{l}3.19 \\
3.20\end{array}$ & $\begin{array}{l}3.31 \\
3.68\end{array}$ & $\begin{array}{l}3.11 \\
1.91\end{array}$ & $\begin{array}{l}2.92 \\
2.60\end{array}$ & $\begin{array}{l}3.07 \\
4.04\end{array}$ & \\
\hline
\end{tabular}

Note- $N N=$ normal-normal; $N A=$ normal-alternating; $A N=$ alternating-normal; $A A_{s}=$ alternating-alternating, same; $A A_{d}=$ alternating-alternating, different.

revealed no statistically significant difference in either average $d^{\prime}$ or $\beta$ between this group and the $\mathrm{AA}_{\mathrm{s}}$ (alternating-alternating condition in the main experiment) treatment group. It is clear that preserving the typing format did not facilitate subjects' recognition performance. In a sense, this result suggests that the orthographical information was not used as a retrieval cue under the experimental treatment of alternating typing cases, and thus provides some empirical support for the use of mixed-type print to eliminate the effect of orthographical differences. The data of the $\mathrm{AA}_{d}$ control group was eliminated from all subsequent analyses.

An ANOVA of d's for the four treatment groups of the factorial design resulted in a significant main effect of word frequency $[\mathrm{F}(1,76)=101.82, \mathrm{p}<.001, \mathrm{MSe}=$ .119], with rare-word recognition markedly superior to common-word recognition. A Newman-Keuls test again revealed a significant $(p<.01)$ effect of rare-word recognition in all conditions. No other main effects or interactions achieved significance at the .05 level. Therefore, the prediction that the magnitude of the word-frequency effect is primarily a function of the differences in orthography for the two word populations has been disconfirmed by these significant word frequency effects.

Inspection of the $\beta$ values for the four groups revealed a slightly different pattern of results. Values of $\beta$ for rare-word recognition were significantly greater $[\mathrm{F}(1,76)=7.63, \mathrm{p}<.01, \mathrm{MSe}=3.76]$ than for common words. More importantly, significantly lower $\beta$ values were found for subjects who received alternating typecase during study (Groups AN and AAs in Table 2) than for those who studied normal (Groups NN and NA) print $[F(1,76)=4.36, p<.05, \quad M S e=13.02]$. No other main effects or interactions were found to be statistically significant.

The distortions in the orthography of rare words failed to alter their subsequent recognition compared to common words similarly distorted. Subjects who studied these irregularly printed words did, however, employ a less stringent response criterion in later recognition testing than did those who studied words with normal print. This occurred regardless of the print type used during recognition.

It is possible that subjects presented with words that had their normal orthographic patterns distorted relied upon a strategy of phonemically encoding the letter strings into identifiable words. This emphasis on the phonemic attributes would not be expected to lead to changes in the magnitude of the word-frequency effect, since the re does not appear to be a differential commonality among rare words as opposed to common words in terms of the phonemic character of a word (Frederiksen, 1971; Landauer \& Streeter, 1973).

\section{GENERAL DISCUSSION}

The results of these two experiments clearly show the robustness of the word-frequency effect in recognition memory. Regardless of the presentation modality and of the testing modality, the recognition superiority of the low-frequency over the high-frequency words was upheld in every experimental condition. Even in the case where subjects were forced to process each word at a letter-by-letter level, the effect was still as strong as in normal reading conditions. Unequivocally, sensory attributes have little to offer for its interpretation.

A semantic interpretation of word recognition can readily account for the higher recognition rate for lowfrequency words found in this study in all conditions of study and test. Reder et al. (1974) suggested that recognition of a to-be-remembered word depends on the recognition of a specific interpretation of the word originally encoded rather than on its physical representation. Since word frequency is a fairly sensitive correlate of the number of senses instantiated in the typical subject (Schnorr \& Atkinson, 1970), and since lowfrequency words (e.g., hippopotamus, aspirin) tend to have no more than one sense, the word-frequency effect in recognition may be attributable to the semantic similarity between the nominal stimulus and the encoded trace for the low-frequency words. For highfrequency words, the greater opportinity for multiple senses to differentiate and be maintained almost ensures recognition failure when the literal copy of the target word is presented in a random fashion during the test.

Glanzer and Bowles (1976) have proposed a similar semantic interpretation of the word-frequency effect. When a to-be-remembered word is presented for study, the subject randomly samples a subset of the possible meanings of the word and marks members of this subset as "old." During testing, the subject again samples from the total set of possible meanings. The probability of a correct recognition decision is dependent upon the proportion of marked meanings within the second sampling. Since low-frequency words have fewer possible meanings than high-frequency words, a greater propor- 
tion of the sample of meanings originally marked is likely to be resampled during recognition testing. It follows that rare words will be better recognized than common words, whatever the sensory modality of presentation.

Either of these models can account for the independence of the word-frequency phenomenon from sensory modality influence. Nonetheless, neither interpretation can account for the enhancement of the wordfrequency effect in the visual condition of Experiment 1. The superiority of rare-word recognition was enhanced when the item was visually displayed for study regardless of the sensory mode of recognition testing. Therefore, encodings of sensory attributes of to-be-remembered words do appear to affect the likelihood of recognizing rare as opposed to common words. This finding cannot be attributed to average word-length differences for the two frequency levels, since word length was matched in this study. Landauer and Streeter (1973) have found, however, that even for words of the same length, common words share a larger number of graphemic constituents with other common words than rare words do with other rare words. Thus, rare words may have had comparatively unique graphemic encodings in the visual presentation of this study even though they were equal in average length to common words. An attempt to facilitate graphemic encodings in Experiment 2, and therefore to enhance rare-word recognition, failed to support this interpretation. However, distortions of normal orthographic patterns in words may only succeed in forcing subjects to rely on phonemic attributes of words rather than enhancing graphemic encoding in the initial identification stage of word processing.

However, certain alterations of the structural characteristics of the two word populations have been shown to differentially affect rare-word recognition in a previous study by Schulman (1967) using only auditory presentation. It was found that increasing the number of syllables in the target word enhanced subsequent recognition if the target was a low-frequency word, but not if it was a high-frequency word. This finding, as well as the enhanced rare-word recognition in the visual input condition of the present study, cannot be explained by reference solely to word meaning. It is apparent that rare-word recognition superiority is a function of both structural and semantic features of to-be-remembered words.

Previous investigators have demonstrated that the structural attributes of a word are encoded with its meaning during the study phase and that the trace of structural encoding operations are retained with the word meaning in long-term storage (Kolers, 1976; Nelson et al., 1974, 1975). It is suggested here that not only are such traces stored with word meaning, but also that access to them is contingent upon access to the sense of the word originally encoded. Thus, the modality of testing would not be expected to affect the superi- ority of rare-word recognition, since there is equivalent access to word meaning in either modality. This interpretation would also account for the elimination of the word-frequency effect when only structural attributes are primed during encoding (Seamon \& Murray, 1976). Similarly, Shulman (1976) found better recognition for very rare words judged by subjects to be meaningful when compared to such words judged to be void of meaning. Therefore, the encoded structural characteristics of rare words would not seem to be a sufficient reason for enhanced recognition, but would appear to be a necessary component. Models which emphasize these characteristics in accounting for the word-frequency effect need reevaluation (e.g., Lockhart, Craik, \& Jacoby, 1976; Underwood, 1969).

The effect of sensory modality on recognition processes and, specifically, on the word-frequency effect in recognition found in this study further emphasizes the need to assess memory phenomena with more than one modality of item presentation (Penney, 1975). Research with a multimode approach serves not only to extend the generalization of memory phenomena, but also may avoid the pitfalls of theory construction based on a single-modality approach.

\section{REFERENCES}

Anderson. J. R.. \& Bower. G. H. Recognition and retrieval processes in tree recall. Psychological Review. 1972. 79. 97-123.

Anderson. J. R.. \& Bower. G. H. A propositional theory of memory. Memony \& Cognition, 1974, 2. 406-412.

BaHRICK, H. P. Two-phase model for prompted recall. Psychological Review. 1970. 77. 215-222.

BERRY, C. Advanced frequency information and verbal response times. Psychontomic Science, 1971, 23. 151-152.

Broadbent. D. E. Word frequency effect and response bias. Psychologicul Review, 1967, 74, 1-15,

Craik, F. I. M., \& Lockhart, R. S. Levels of processing: A framework for memory research. Journal of Verbal Learning and Verbal Behavior, 1972, 11.671-684.

Crowder, R. G. Principles of learning and memon. Hillsdale. N.J: Lawrence Erlbaum, 1976.

FRederiksen, J. R. Statistical decision model for auditory word recognition. Psychological Review, 1971, 78. 409-419.

Freeman. P. R. Tracts for computers No. $X X X$ : Table of d's and $\beta$. London: Cambridge University Press. 1973.

Glanzer. M.. \& Bowles. N. Analysis of the word frequency effect in recognition memory. Joumal of Experimental Psychology: Human Learning and Memory, 1976, 2, 21-31.

GREGG, V. Word frequency. recognition and recall. In J. Brown (Ed.). Recall and recognition. New York: Wiley, 1976.

HaLL, J. F. Learning as a function of word frequency. American Journal of Psychology. 1954, 67, 138-140.

Kahneman, D. Attention and effort. Englewood Clifts. N.J: Prentice-Hall. 1973.

Kinsbourne, M.. \& George. J. The mechanism of the wordfrequency effect on recognition memory. Journal of Verbal Learning and Verbal Behavior. 1974, 13. 63-69.

Kintsch. W. Learning. memory and conceptual processes. New York: Wiley, 1970. (a)

KintsCH. W. Models for tree recall and recognition. In D. A. Norman (Ed.). Models of human memory. New York: Academic Press. 1970. (b) 
Kolers. P. A. Reading a year later. Journal of Experimental Psichology: Human Learning and Memon: 1976. 2. 554-565.

Landauer. T. K., \& Streeter. L. A. Siructural differences between common and rare words: Failure of equivalence assumptions for theories of word recognition. Journal of Verhal Learming and Verbal Behavior. 1973, 12, 119-131.

Lókhart, R. S. Craik, F, I. M.. \& Jacoby. L. Depth of processing. recognition and recall. In J. Brown (Ed.). Recull and recognition. New York: Wiley. 1976.

Mayzner. M. S., d Tresselt. M. E. Anagram solution tines: A function of letter order and word frequency. Journal of Experimental Psychology: 1958. 56. 376.379.

Mc Cormack. P. D. Recognition memory: How complex a retrieval system? Canadian Joumal of Psychology, 1972, 26 19.37.

Nelson, D. L., Brooks. D. H., \& Wheeler, J. W. Sensory and meaning features in stimulus recognition and associ. atise retrieval. Joumal of Experimental Psychology: Human Le'aming and Memon' 1975. 1.711.719.

Nelson. D. L.. Wheeler, J. W., Borden, R. C., d Brooks. D. H. Levels of processing and cueing: Sensory versus meaning features. Joumal of Experimental Psichologiv. 1974. 103.971.977.

Paivio. A.. Yuille. J. C.. \& Madigan. S. A. Concreteness. imagery, and meaningfulness values for 925 nouns. Journal of Experimemtal Psychology. 1968. 76. 1.25.
Penney, C. G. Modality effects in short-term verbal memory. Psichological Bulletin. 1975, 82, 68-84.

RFder, L. M., ANDERSON. J. R., \& Bjork, R. A. A semantic interpretation of encoding speciticity. Journal of Experimental Psichology. 1974, 102, 648-656.

Seamun, J. G. \& Murray, P. Depth of processing in recall and recognition memory: Differential effects of stimulus meaningfulness and serial position. Journal of Experimental Psirhologl: Human Learning and Memony. 1976, 2. 680-687.

SCHNORR. J. A.. \& AtKInson, R. C. Study position and item differences in the short-and long-term retention of paired associates learned by imagery. Journal of Verbal Learning and Verbal Bihavior, 1970, 9. 614-622.

SCHULman, A. I. Word length and rarity in recognition memory. Psichonomic Science, 1967. 9. 211-212.

Schulman, A. I. Memory for rare words previously rated for familiarity. Joumal of Experimental Psychology: Human Learning and Memon. 1976. 2. 301-307.

UNDERWOOD. B. J. Attributes of memory. Psychological Revien. 1969, 76. 559-573.

ZiPF. G. K. The psychology of language. Boston: HoughtonMittlin. 19.35.

(Received for publication January 15,1978 ; accepted February 24, 1978.) 